\title{
Hf-Nd Isotope Systematics of Kimberlites: Relevance to Terrestrial Hf- Nd systematics
}

Nowell., G.M. ${ }^{1.2}$, Kempton, P.D. ${ }^{2}$, Pearson, D.G. ${ }^{2}$

1. Department of Geological Sciences, Durham University, South Road, Durham DH1 3LE. U.K.

2. NERC Isotope Geosciences Laboratory, Kingsley Dunham Centre, Keyworth, Nottingham NG12 5GG, U.K.

\section{Introduction}

The Hf-Nd isotopic composition of kimberlites, lamproites and megacrysts presented by Nowell et al. (1998a,b) and Nowell and Pearson (1998) have significance not only for constraining models for their own petrogenesis but also for understanding the wider terrestrial Hf-Nd isotope budget and the nature of global reservoirs.

\section{Terrestrial Hf-Nd isotope systematics}

Blichert-Toft and Alberède (1997) noted that in Hf-Nd isotope space, the mantle-crust array was displaced above their revised Bulk Silicate Earth (BSE) value determined from a study of 25 chondrites (Figure 1a). They also noted that, given the observed $\mathrm{Hf} / \mathrm{Nd}$ ratios of the two most prominent terrestrial components at the Earth's surface, depleted mantle (DM) and continental crust (CC), it is not possible to account for the Hf-Nd isotope geochemistry of BSE. As $\mathrm{Hf} / \mathrm{Nd}_{\mathrm{DM}}$ is greater than $\mathrm{Hf} / \mathrm{Nd}_{\mathrm{CC}}$, the mixing hyperbola is concave downward and lies above BSE (Figure $1 \mathrm{~b}$ ). Therefore, in order to account for the Hf-Nd composition of BSE Blichert-Toft and Alberède (1997) found it was necessary to invoke the existence of at least a third component (referred to as $\mathrm{X}$ in Figure 1c) which would plot below BSE and the mantle array in Hf-Nd space. This 'missing' component would compliment DM and CC as components of BSE.
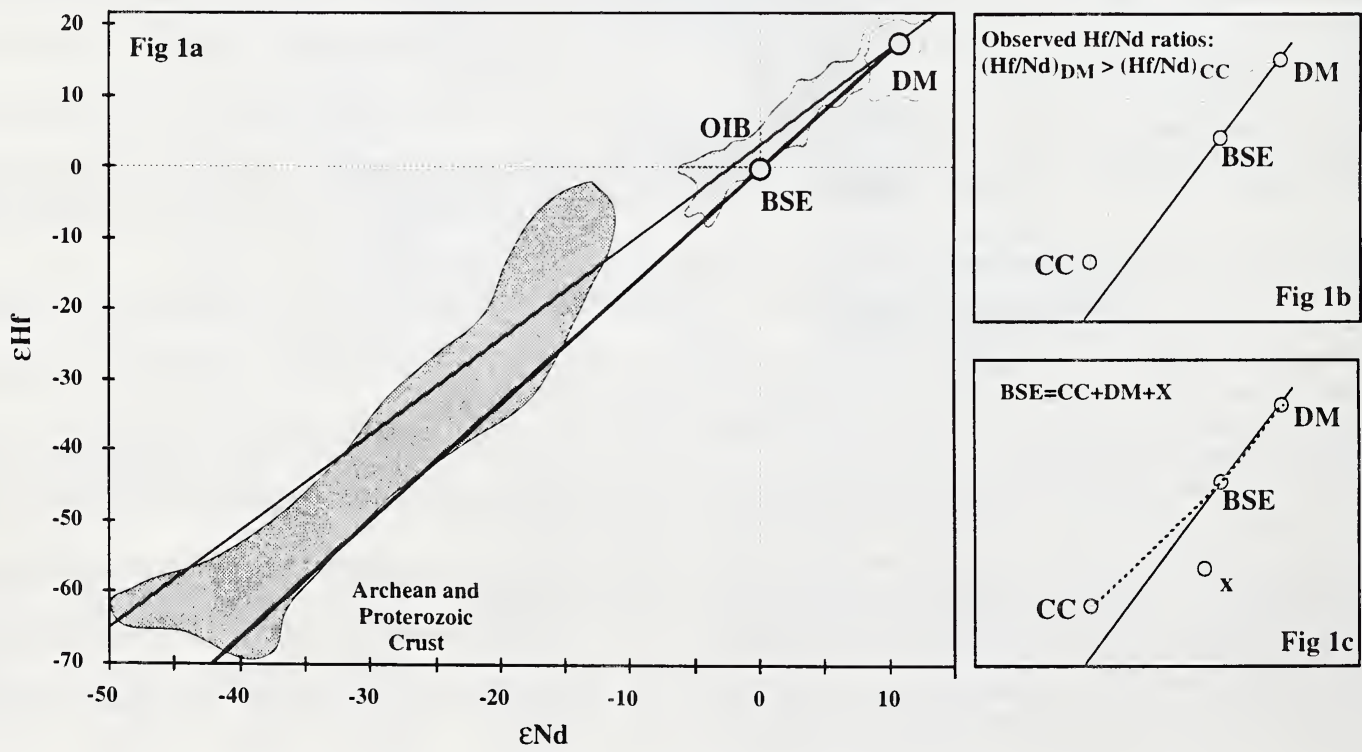

Figure 1. (a) Hf-Nd isotope variation of oceanic basalts and Precambrian crustally-derived granites. (b) Sketch of mixing hyperbola for $\mathrm{CC}+\mathrm{DM}$ given their observed $\mathrm{Hf} / \mathrm{Nd}$ ratios. (c) BSE Hf-Nd composition requires the existence of a 'missing' component $(\mathrm{X})$ that plots below the line linking DM with BSE. DM= Depleted Mantle, BSE=Bulk Silicate Earth, $\mathrm{OIB}=$ Ocean Island Basalt, $\mathrm{CC}=$ Continental Crust. 
Although the existence of a third terrestrial component existing below the $\mathrm{Hf}-\mathrm{Nd}$ mantle array can be inferred from the Hf-Nd systematics of DM-CC-BSE, Blichert-Toft and Alberède (1997) noted that there was no direct isotopic evidence for it existence, and concluded that if it existed it must reside deep enough in the mantle that it no longer constitutes a dominant component of the source of modern oceanic or continental basalts. In order to evolve Hf-Nd isotope ratios below the DM-BSE line (heavy line in Figure 1a) this component would have to represent an ancient melt that was generated in the presence of residual garnet. Blichert-Toft and Alberède (1997) argued that the most plausible candidate for such a component is old subducted oceanic crust.

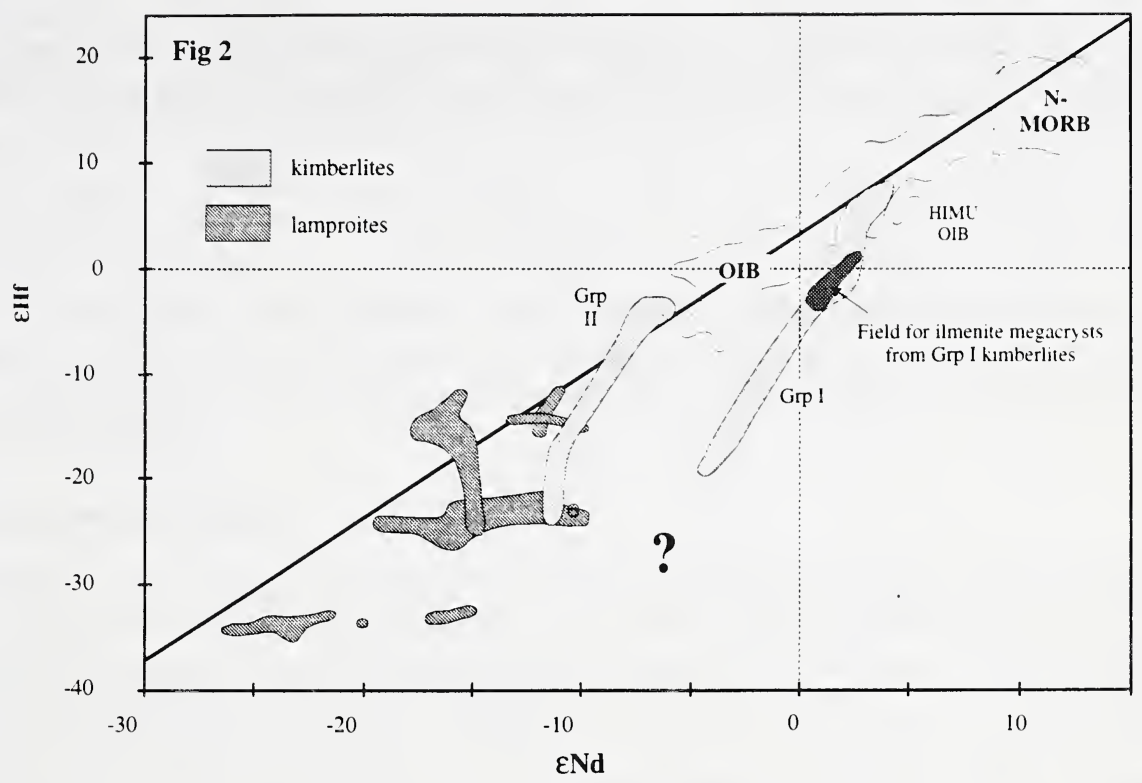

Figure 2. Hf-Nd isotopic composition of kimberlites (Nowell et al., 1998a), lamproites (Nowell et al., 1998b) and megacrysts (Nowell and Pearson, 1998).

\section{Hf-Nd isotope composition of Kimberlites, Lamproites and Megacrysts}

The new Hf isotope data for kimberlites, lamproites and megacrysts (Figure 2) are the only terrestrial samples yet analysed to show such extreme trends toward compositions below the mantlecrust array in Hf-Nd isotope space. These samples therefore provide the first direct isotopic evidence for the existence of a component with $\mathrm{Hf}-\mathrm{Nd}$ isotopic compositions appropriate for the component invoked by Blichert-Toft and Alberède (1997) to account for BSE. The negative $\Delta \varepsilon H f$ signatures (i.e. values below the Hf-Nd mantle array) of kimberlites and lamproites imply that an ancient melt. necessarily generated in the presence of garnet, must exist within their source region (Nowell et al., 1998a,b). In addition, Hf isotope data from kimberlitic megarysts (Nowell and Pearson, 1998) suggests that this component may be located in the sub-lithospheric mantle. We therefore concur with Blichert-Toft and Alberède (1997) that the most likely 'missing' mantle component in Hf-Nd isotope space represents ancient subducted oceanic crust originally derived from a garnet-bearing source. 
The departure of HIMU (High $\mu$; where $\mu={ }^{238} \mathrm{U} /{ }^{204} \mathrm{~Pb}$ ) ocean islands away from the main Hf$\mathrm{Nd}$ mantle array in a similar direction to Group I kimberlites and megacrysts suggests a contribution from subducted oceanic crust and is entirely consistent with the models for HIMU based on $\mathrm{Pb}$ and Os isotopes.

\section{References}

Blichert-Toft, J., Albererde, F., 1997, The Lu-Hf Isotope Geochemistry of Chondrites and the Evolution of the Mantle Crust System: Earth Planet. Sci. Lett., 148, p. 243-258.

Nowell, G.M., Pearson. D.G., 1998, Hf Isotope Constraints on the Genesis of Kimberlitic Megacrysts: Evidence for a Deep Mantle Component in Kimberlites: this volume.

Nowell, G.M., Pearson, D.G., Kempton, P.D., Noble, S.R., and Smith. C.B., 1998a. The Source Regions/Components of Kimberlites: Constraints from Hf-Nd Isotope Systematics: this volume.

Nowell, G.M., Pearson, D. G., Kempton, P.D., Irving, A.J., and Turner, S., 1998b, A Hf Isotope Study of Lamproites: Implications for Their Origins and Relationship to Kimberlites: this volume. 